\title{
Effects of a 12-hour shift on mood states and sleepiness of Neonatal Intensive Care Unit nurses
}

\author{
Efeitos de um turno de 12 horas nos estados de humor e na sonolência \\ de enfermeiros de unidade de tratamento intensivo neonatal \\ Efectos de un turno de 12 horas en los estados de ánimo y somnolencia de \\ las enfermeras de la Unidad De Cuidados Intensivos Neonatales
}

Tadeu Sartini Ferreira ${ }^{1}$, Clarice Zinato Moreira ${ }^{2}$, James Guo ${ }^{3}$, Franco Noce $^{4}$

How to cite this article:

Ferreira TS, Moreira CZ, Guo J, Noce F. Effects of a 12-hour shift on mood states and sleepiness of Neonatal Intensive Care Unit nurses. Rev Esc Enferm USP. 2017;51:e03202. DOI: http://dx.doi.org/10.1590/S1980-220X2016033203202

${ }^{1}$ Hospital Alberto Cavalcanti, Belo Horizonte, MG, Brazil.

${ }^{2}$ Hospital Mater Dei, Belo Horizonte, MG, Brazil.

${ }^{3}$ Cornell University, Ithaca, NY, United States of America.

${ }^{4}$ Universidade Federal de Minas Gerais, Laboratório de Psicologia do Esporte, Belo Horizonte, MG, Brazil.

\begin{abstract}
Objective: To assess the effect of a 12-hour shift on mood states and sleepiness at the beginning and end of the shift. Method: Quantitative, cross-sectional and descriptive study. It was conducted with 70 neonatal intensive care unit nurses. The Brunel Mood Scale (BRUMS), Karolinska Sleepiness Scale (KSS), and a socio-demographic profile questionnaire were administered. Results: When the KSS and BRUMS scores were compared at the beginning of the shift associations were found with previous sleep quality $(\mathrm{p} \leq 0.01)$, and quality of life $(\mathrm{p} \leq 0.05)$. Statistical significant effects on BRUMS scores were also associated with previous sleep quality, quality of life, liquid ingestion, healthy diet, marital status, and shift work stress. When the beginning and end of the shift were compared, different KSS scores were seen in the group of all nurses and in the night shift one. Significant vigor and fatigue scores were observed within shift groups. Conclusion: A good night's sleep has positive effects on the individual's mood states both at the beginning and the end of the shift. The self-perception of a good quality of life also positively influenced KSS and BRUMS scores at the beginning and end of the shift. Proper liquid ingestion led to better KSS and BRUMS scores.
\end{abstract}

DESCRIPTORS

Nursing; Shift Work; Sleep; Mood Disorders.
Corresponding author:

Franco Noce

Av. Presidente Antônio Carlos, 6627 - Pampulha CEP 31270-901 - Belo Horizonte, MG, Brazil fnoce@hotmail.com
Received: 08/22/2016 Approved: 12/20/2016 


\section{INTRODUCTION}

Intensive care unit (ICU) nurses have to provide high quality care for fragile patients ${ }^{(1)}$. Such care occurs in a technology-rich and rapidly changing environment, which gives rise to both human and nonhuman sources of error ${ }^{(2)}$. Workers with high demands have significantly enhanced risks of developing psychiatric disorders, with stress and fatigue as important contributing factors. Both acute fatigue and chronic fatigue negatively affect quality of life and performance ${ }^{(2)}$.

Stress is a complex phenomenon that includes the psychophysiological stress event and its perception, intrinsic and extrinsic mediating factors, and the response ${ }^{(3)}$. It has been suggested that perceptions of stress in work situations are more influential than the stressors themselves. Stress can affect the physical health of nurses, manifesting as headaches, skin rashes, intestinal disorders and weight variations. Ultimately, and importantly, it affects the quality of patient care. Care of children with poor prognoses, workload, distrust of nurses' opinions by physicians, lack of knowledge and the limited experience of staff are possible stressors ${ }^{(4)}$. In addition, lack of support and respect within a team, long hours of work and the responsibility of taking care of critically ill patients, can be added to the list of stressors ${ }^{(5)}$. ICU nurses must also deal with the patients' family members ${ }^{(3)}$.

Intensive care unit nurses usually work shifts; according to a number of studies 12 -h shifts are associated with difficulty in staying awake, sleep deprivation and a threefold risk of making mistakes ${ }^{(6-7)}$. A number of studies have quantified the negative impact of sleep deprivation on shift work, fatigue, performance and learning ${ }^{(8)}$.

Comparisons between day and night shift workers are frequently performed ${ }^{(9-11)}$. Night shift workers have disrupted circadian rhythms as they sleep when melatonin is low and cortisol is high ${ }^{(12)}$. Shift working can have negative effects on mental health such as the burnout syndrome which has been widely studied in ICU nurses ${ }^{(13-14)}$. However, the effects of a shift on mood states need further clarification. This study aimed to contribute to the understanding of the effects of a 12 -h shift on mood states and sleepiness in nurses, and their underlying causes.

\section{METHOD}

A cross-sectional quantitative and qualitative study was conducted with 70 neonatal intensive care unit (NICU) nurses, who worked either night or day shifts at the Vila da Serra Hospital in Belo Horizonte, Brazil. Inclusion criteria were as follows (1) working at the ICU (2) informed consent signing upon participation agreement. All NICU nurses were included and coincidentally no one was on vacation or leave license. Overall, they had 6 years of nursing experience and 5 months of employment at the ICU. The maternity hospital was accredited by the Canadian Council for Health Services Accreditation in 2011. This study was approved by the University Center of Belo Horizonte Research Ethics Committee (005/2011), and participants signed an informed consent form after a detailed explanation of the study. All 70 NICU nurses agreed to participate and no withdrawals were observed.

We assessed the effect of a 12-hour shift on mood states and sleepiness at the beginning and end of the shift through the Brunel Mood Scale (BRUMS) and Karolinska Sleepiness Scale (KSS), respectively. The BRUMS was a translated and validated Portuguese version ${ }^{(15)}$. It consisted of 24 items to assess mood change in the six mood dimensions - tension, depression, anger, vigor, fatigue, and confusion.

The Karolinska Sleepiness Scale ${ }^{(16)}$ is a 9-grade Likert scale - ranging from 1(very alert) to 9 (very sleepy-fighting sleep). The KSS is a validated scale for the assessment of sleepiness ${ }^{(17)}$, and a high level of sleepiness was defined as a score $\geq 7^{(16)}$.

The socio-demographic questionnaire comprised questions covering age, marital status, sex, profession (years after graduation, experience in that specific position, the reason to work in shifts, other jobs), sleepiness (sleep quality, number of hours slept, number of hours awake) and quality of life. At the end of the shift, nurses filled out another questionnaire about workload, food and liquid intake, food quality, rest time, number of patients, complexity of the cases, number of interventions made, shift stress and main stress causes during that day.

\section{Statistical ANAlysis}

Analyses were performed using the IBM SPSS statistical software version 21.0 at a 5\% significance level. Sociodemographic profile data were displayed as absolute frequencies and percentages. We compared the KSS and BRUMS scores of different groups at the beginning and end of the shift using the Mann-Whitney Test for two groups and the Kruskal-Wallis Test for more than two. Also, a correlation between the KSS scores and each of the 6 BRUMS mood states was tested by Spearman correlation at the beginning and end of the shift.

\section{RESULTS}

Most of the nurses were women (97\%), with a mean age of 30 years, and married (60\%). Overall, they had 6 years of nursing experience and 5 months of employment at the ICU. Most did not have other employment (76\%) and worked during day shifts (51.4\%). In addition, $68 \%$ percent declared their quality of life as satisfactory. Nurses were questioned about their main reasons to work in $12-\mathrm{h}$ shifts. They were: hospital demands (40\%), more time for other activities (25\%), and personal preferences (20\%).

\section{SHIFT WORK START TIME}

Nurses formally start the early shift at 6am and the night shift at $6 \mathrm{pm}$. However, nurses typically arrive earlier for shift changes, when important information regarding patients health status is provided to the next professional on duty.

\section{SLEEPINESS SCORES}

Regarding the Karolinska Sleepiness Scale (KSS), day shift nurses predominantly declared themselves as alert 
(44\%) while night shift nurses declared themselves as either very alert $(39.4 \%)$ or alert $(36.4 \%)$ - see Figure 1 . The distribution of the KSS scores across shifts was significantly different $(\mathrm{p}<0.001)$.

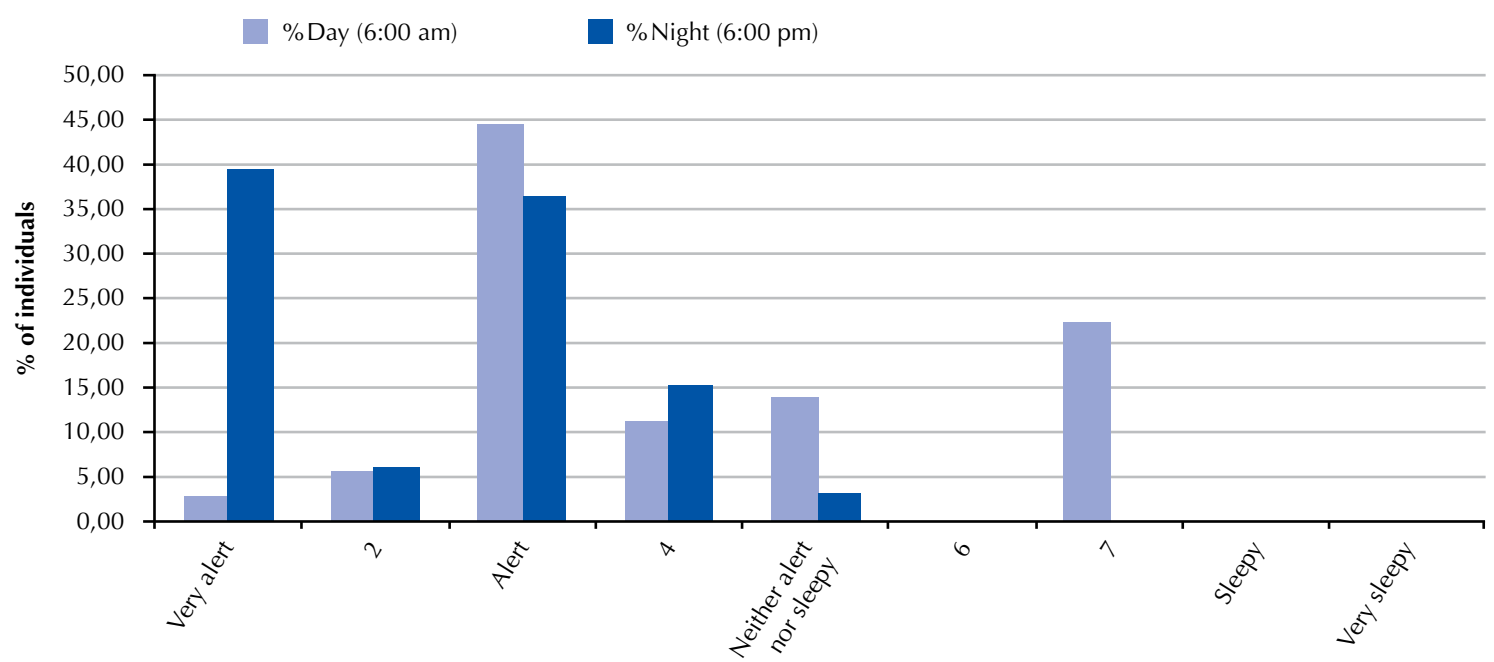

Figure 1 - KSS scores for the beginning of day and night shifts - Belo Horizonte, MG, Brazil, 2012.

Lower scores were found in "day shift" ( $p \leq 0.001)$, "good previous sleep quality" ( $\mathrm{p} \leq 0.01)$, and "good quality of life" ( $\mathrm{p} \leq 0.05)$.

\section{MOOD}

No significant differences between shifts were found BRUMS scores for the beginning of shifts.

When BRUMS` scores were analyzed within groups, significant differences were found in "good night's sleep" (better Tension, Vigor and Fatigue scores), "good quality of life" (better Depression, Anxiety and Vigor scores) and "marital status" groups. Those who either single or married, had better Confusion and Anxiety scores than divorced individuals.
Both Fatigue $\left(\rho=0.341^{* *}\right)$ and Vigor $\left(\rho=-0.348^{* * *}\right)$ showed significant correlations between KSS and dimensions.

\section{END OF SHIFT WORK}

Nurses formally finished their shifts either at 6am or at $6 \mathrm{pm}$ but typically spent extra time during the shift changing process before leaving.

\section{SLEEPINESS SCORES}

Although night nurses were more likely to experience a high level of sleepiness, there was no significant difference in KSS scores between shifts $(\mathrm{p}=0.81)$. - See Figure 2 .

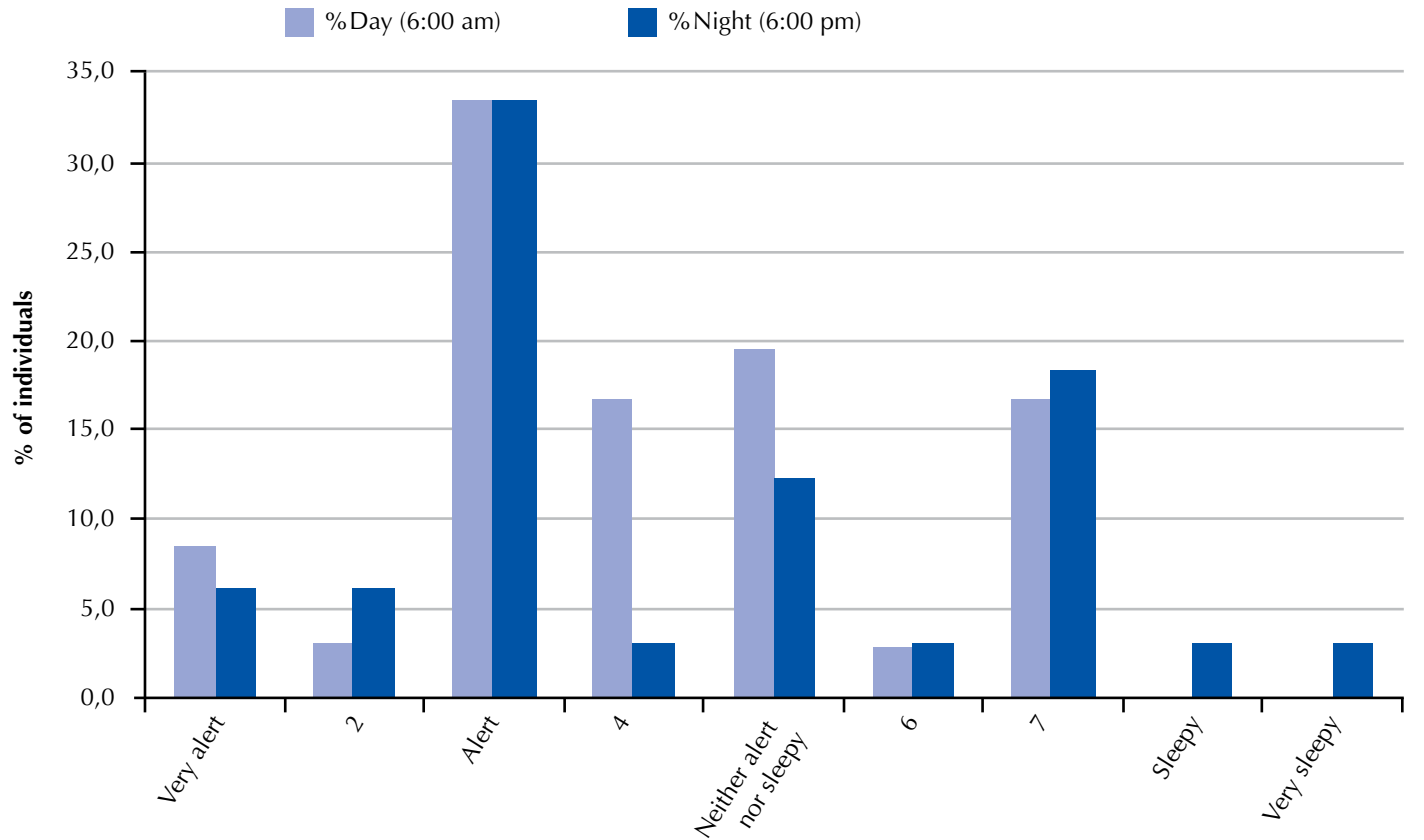

Figure 2 - KSS - End of shift work - Belo Horizonte, MG, Brazil, 2012. 
At the end of the shift, nurses evaluated their own liquid ingestion and diet. They also filled out a questionnaire about patient complications, workload and stress levels during their shift. Lower KSS scores were found in 'good quality of life` $(p \leq 0.05)$ and 'liquid ingestion` $(p \leq 0.01)$ groups.

\section{MOOD}

All six mood dimensions showed no significant differences between shifts.

Better mood scores were found in "good quality of life" (Tension, Depression, Anxiety, Fatigue, and Confusion), "good night's sleep" (Tension and Fatigue), "healthy diet" (Anxiety and Fatigue), "proper liquid ingestion" (Tension, Depression, Anxiety, Vigor, Fatigue, and Confusion), and "minor stress" (Tension and Fatigue) groups. Confusion was the only dimension that did not exhibit correlation with KSS scores.

A total of $71 \%$ of participants characterized the workload as medium (scale: light/medium/heavy), 68\% characterized the work complexity as medium (low/medium/high), and $58 \%$ characterized their shift work stress level as minor (no stress/minor stress/major stress). The main causes of stress were: workload, patient's severity and interpersonal relationships. $95 \%$ of the nurses had some time to rest for a period between 20 minutes to 5 hours (Avg. $1.7 \mathrm{~h} \pm 1.4$ ).

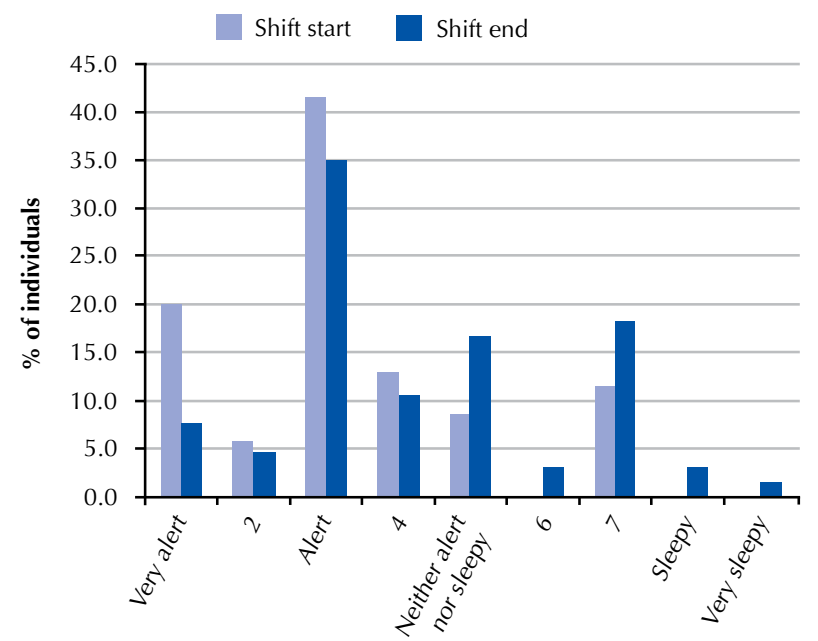

Moreover, we assessed the existence of patient complications and their severity levels. $34.3 \%$ dealt with patient complications. Out of 33 total complications, 22 were classified as "routine" and 11 as "severe". With regard to nurses' nutrition, $88 \%$ ate during the shift. Their diet mainly consisted of bread, coffee, milk and fruit. 53.7\% did not consider their diet healthy. Only $38.8 \%$ declared to drink enough water during the shift.

\section{SHIFT BEGINNING VS END OF SHIFT}

All analyses in this section refer to the comparison between the beginning and end of the shift. KSS scores are shown on Table 1 and on Figure 3.

Table 1-KSS and BRUMS scores-Belo Horizonte, MG, Brazil, 2012.

\begin{tabular}{|c|c|c|c|c|c|}
\hline & & $\begin{array}{c}\text { KSS } \\
\text { (Avg.) }\end{array}$ & $\begin{array}{c}\text { Sig. } \\
\text { (2-tailed) }\end{array}$ & $\begin{array}{l}\text { Mood States } \\
\text { Scores }\end{array}$ & $\begin{array}{c}\text { Sig. } \\
\text { (2-tailed) }\end{array}$ \\
\hline \multirow{2}{*}{$\begin{array}{l}\text { All nurses } \\
\quad(n=68)\end{array}$} & Start & 3.30 & \multirow{2}{*}{$.001^{* * *}$} & $55.91(\mathrm{~V}) ; 46.10(\mathrm{~F})$ & \multirow{2}{*}{$\begin{array}{l}.000^{* * *}(\mathrm{~V}) \\
.000^{* * *}(\mathrm{~F})\end{array}$} \\
\hline & End & 4.30 & & $49.06(\mathrm{~V}) ; 50.37(\mathrm{~F})$ & \\
\hline \multirow{2}{*}{$\begin{array}{l}\text { Day shift } \\
(\mathrm{n}=36)\end{array}$} & Start & 4.17 & \multirow{2}{*}{.870} & $55.22(\mathrm{~V}) ; 45.97(\mathrm{~F})$ & \multirow{2}{*}{$\begin{array}{c}.001^{* * *}(\mathrm{~V}) \\
.003^{* *}(\mathrm{~F})\end{array}$} \\
\hline & End & 4.11 & & $49.39(\mathrm{~V}) ; 49.08(\mathrm{~F})$ & \\
\hline \multirow{2}{*}{$\begin{array}{l}\text { Night shift } \\
(\mathrm{n}=32)\end{array}$} & Start & 2.24 & \multirow{2}{*}{$.003^{* *}$} & $56.81(\mathrm{~V}) ; 46.10(\mathrm{~F})$ & \multirow{2}{*}{$\begin{array}{l}.006^{* *}(\mathrm{~V}) \text {; } \\
.019^{*}(\mathrm{~F})\end{array}$} \\
\hline & End & 4.41 & & 49.10(V); $51.58(\mathrm{~F})$ & \\
\hline
\end{tabular}

***:Significant difference at the 0.001 level. ${ }^{* *}$ Significant difference at the 0.01 level. *Significant difference at the 0.05 level. Fatigue (F), Vigor (V).

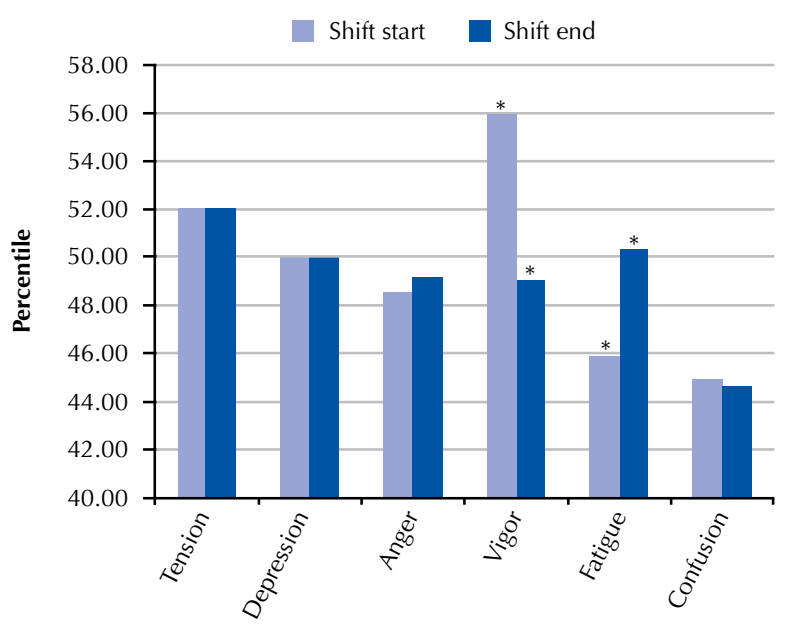

Figure 3 - KSS and BRUMS scores for the beginning and the end of shifts - Belo Horizonte, MG, Brazil, 2012.

\section{DISCUSSION}

Increases in sleepiness and declines in neurobehavioral performance appear when the time spent in bed decreases to $<5-6 \mathrm{~h}^{(11)}$. Significant daytime sleepiness was not observed among individuals from different shifts, as previously described ${ }^{(18)}$.

Day shift nurses slept less than 6 hours and exhibited higher scores for sleepiness at the beginning of the shift than did the night shift nurses $(p=.000)-$ See Figure 1. Also, $22 \%$ of day shift nurses started working at a high level of sleepiness (KSS $\geq 7$ ). Overall they slept by $9 \mathrm{pm}$ and woke up at $3 \mathrm{am}$, a time when melatonin levels are high, cortisol levels are low, and core body temperature is $\operatorname{low}^{(9)}$. These factors contributed to an increased sleepiness, in conformity with the circadian process, which corresponds to the oscillation of sleep propensity throughout the biological day ${ }^{(9)}$. Sleeping less than 6 hours nearly doubles the risk for workplace injury compared to $\geq 7 \mathrm{~h}$ sleep ${ }^{(19)}$. Based on that, nurses should have slept at $8 \mathrm{pm}$. Nevertheless, considering $60 \%$ of them were married, housework and home responsibilities possibly limited their sleep time ${ }^{(20-22)}$. Transportation is described as the second main cause of stress and is another cause of limited sleep time ${ }^{(20-21)}$.

At the end of the shift, there was no significant difference in KSS scores between day and night nurses $(\mathrm{p}=0.81)$. Considering all nurses, significantly higher KSS scores were found at the end than at the beginning of the shift $(p=.001)$. Day nurses exhibited lower sleepiness when they ended than when they started (.870), possibly due to an elevated score at 
the beginning of the shift. Only night nurses had subjects in the two highest levels of the scale and reported significantly higher levels of sleepiness $(\mathrm{p}=.003)$. Our data are consistent with another study showing night nurses appeared to be more vulnerable than day nurses to sleepiness by the end of their work shift ${ }^{(11)}$.

In regards to mood states, no differences were found between shifts in the beginning and end of the work day. Not surprisingly, according to the intra group analyses, nurses had decreased scores in vigor and increased scores in fatigue after the completion of the $12-\mathrm{h}$ shift.

Interesting data were observed from analyzing the groups. Sleeping well had beneficial mood effects on vigor $(\mathrm{p}=.005)$, tension $(\mathrm{p}=.001)$ and fatigue $(\mathrm{p}=.000)$ at the beginning of the shift. Likewise, it exhibited benefits at the end of shifts for tension $(\mathrm{p}=.001)$ and fatigue $(\mathrm{p}=.000)$.

Nurses reporting a good quality of life slept well $(\mathrm{p}=.000)$ and exhibited lower sleepiness ( $\mathrm{p}_{\text {beginning }}=.028, \mathrm{p}_{\text {end }}=.027$ ), depression $\left(\mathrm{p}=.001_{\text {beginning }}, \mathrm{p}_{\text {end }}=.010\right)$, anger $\left(\mathrm{p}_{\text {beginning }}=.006\right.$, $\left.\mathrm{p}_{\text {end }}=.000\right)$, and fatigue $\left(\mathrm{p}_{\text {beginning }}=.000, \mathrm{p}_{\text {end }}=.004\right)$ for both the beginning and the end of the shift. Higher scores for vigor at the beginning and lower scores for confusion and tension at the end were found as well. Previous studies have found an association between sleep and quality of life ${ }^{(10,23)}$ and sleep and mental disorders ${ }^{(24-25)}$. Although generalizations of this data are limited by our transversal study, nurses with a chronic exposure to poor quality of sleep and higher levels of anger, depression and fatigue might be at higher risk to develop mental disorders. According to our data, a good quality of life was not associated with age, marital status, work experience or shift. Contributing factors to a better quality of life were not assessed in this study.

The effects of hydration status on cognitive performance and mood have been studied ${ }^{(26)}$. Our data revealed advantages of having proper liquid ingestion during the shift, such as reduced sleepiness $(\mathrm{p}=.005)$ and positive influences on the six mood states: tension ( $\mathrm{p}=.000)$, depression $(\mathrm{p}=.000)$, anger $(\mathrm{p}=.001)$, vigor $(\mathrm{p}=.012)$, fatigue $(\mathrm{p}=.000)$, and confusion $(p=.044)$. Although levels of hydration were not assessed, we found evidence of the importance of liquid intake during the shift. Further investigation is necessary.
Approximately 25\% of the nurses declared to have chosen to work in 12 -h shifts in order to have more time, contributing to a more flexible working life ${ }^{(27-28)}$. A literature review found some studies that concluded that 12 -hour shifts can potentially improve nurses` satisfaction, patient care quality and efficient management of the nursing unit ${ }^{(27-29)}$. At the same time, it reported potentially serious error-related consequences to patient care ${ }^{(6-7)}$. One study performed with 502 critical care nurses concluded the risk of error proportionally increases with the shift length, due to nurses diminishing vigilance ${ }^{(6)}$.

Overall findings suggest a good night's sleep has positive effects on the individual's mood states both at the beginning and the end of the shift. It can also reduce the sleepiness at the beginning of the shift. The self-perception of a good quality of life also positively influenced KSS and BRUMS scores at the beginning and the end of the shift. Ultimately, nurses who declared a proper liquid ingestion during the shift exhibited better KSS and BRUMS` scores.

\section{CONCLUSION}

Nurses should take care of their own mental and physical health, seeking a good quality of life, as possible. Although 12-h shifts are potentially hazardous both to the patients and the nursing staff, reducing shift length may not be a simple task, since many circumstances need to be considered. What would be the impact on nurses incomes? Would there be enough qualified staff members? Would it be economically viable for hospitals and insurance companies? A thorough analysis of the issue needs to be conducted, and decisions made should result in a greater balance of benefit over risk for both the patients and nurses.

\section{RESEARCH LIMITATIONS}

Only one ICU was part of this research and it describes an environment of a private hospital. Moreover, the number of participants does not allow any generalizations.

\section{Declaration of Interest Statement}

The authors have no conflicts of interest to declare. This study was not supported by any funding agency.

\section{RESUMO}

Objetivo: Avaliar o efeito de um turno de 12 horas nos estados de humor e na sonolência ao início e ao final do turno. Método: Estudo quantitativo, transversal e descritivo. $\mathrm{O}$ estudo foi realizado com 70 profissionais de enfermagem de unidades de terapia intensiva neonatal. A Escala de Humor de Brunel (BRUMS), a Escala de Sonolência de Karolinska (KSS) e o Questionário Perfil Sociodemográfico foram aplicados. Resultados: Quando os escores da KSS e da BRUMS foram comparados no início do plantão, associações foram encontradas entre a qualidade do último sono $(p \leq 0,01)$ e a qualidade de vida $(p \leq 0,05)$. Efeitos significativamente estatísticos nos escores da BRUMS também foram associados às variáveis: qualidade do sono, qualidade de vida, ingestão de líquido, dieta saudável, estado civil e estresse no plantão. Quando o início e o fim do turno foram comparados, diferentes escores para sonolência foram vistos no grupo de todos os enfermeiros e no turno da noite. Escores significativos de vigor e de fadiga foram observados intergrupos. Conclusão: Uma boa noite de sono tem efeitos positivos sobre os estados de humor tanto no início quanto ao final do turno. A autopercepção de uma boa qualidade de vida também influenciou positivamente os escores da KSS e da BRUMS no início e ao final do turno. A ingestão adequada de líquidos levou a melhores pontuações KSS e BRUMS.

Enfermagem; Trabalho em Turnos; Sono; Transtornos do Humor. 


\section{RESUMEN}

Objetivo: Evaluar el efecto de un turno de 12 horas en estados de ánimo y somnolencia al principio y al final del turno. Método: Estudio cuantitativo, transversal y descriptivo. Se realizó con 70 enfermeras de unidades de cuidados intensivos neonatales. Se administró la Escala de Humor Brunel (BRUMS), la Escala de Somnolencia de Karolinska (KSS) y un cuestionario de perfil sociodemográfico. Resultados: Cuando se compararon las puntuaciones de KSS y BRUMS al comienzo del turno se encontraron asociaciones con calidad de sueño previa $(\mathrm{p} \leq 0,01)$ y calidad de vida $(\mathrm{p} \leq 0,05)$. Los efectos estadísticos significativos en las puntuaciones de BRUMS también se asociaron con la calidad previa del sueño, la calidad de vida, la ingestión de líquidos, la dieta saludable, el estado civil y el estrés laboral por turnos. Cuando se compararon el comienzo y el final del turno, se observaron diferentes puntuaciones de KSS en el grupo de todos los enfermeros y en el turno de noche. Se observaron puntuaciones significativas de vigor y fatiga dentro de los grupos de turnos. Conclusión: Dormir bien de noche tiene efectos positivos en los estados de ánimo del individuo tanto al principio como al final del turno. La autopercepción de una buena calidad de vida también influyó positivamente en las puntuaciones KSS y BRUMS al inicio y al final del turno. La ingesta de líquidos adecuada condujo a mejores puntuaciones KSS y BRUMS.

\section{DESCRIPTORES}

Enfermería; Trabajo por Turnos; Sueño; Transtornos del Humor.

\section{REFERENCES}

1. Almeida FA, Moraes MS, Cunha MLR. Taking care of the newborn dying and their families: nurses' experiences of neonatal intensive care. Rev Esc Enferm USP. 2016;50(n.spe):122-9. DOI: http://dx.doi.org/10.1590/S0080-623420160000300019

2. Montgomery VL. Effect of fatigue, workload, and environment on patient safety in the pediatric intensive care unit. Pediatr Crit Care Med. 2007;8(2 Suppl):S11-6.

3. Sawatzky JA. Stress in critical care nurses: actual and perceived. Heart Lung. 1996;25(5):409-17.

4. Williamson S. Job satisfaction and dissatisfaction amongst neonatal nurses. Midwifery. 1993;9(2):85-95.

5. Demir A, Ulusoy M, Ulusoy MF. Investigation of factors influencing burnout levels in the professional and private lives of nurses. Int J Nurs Stud. 2003;40(8):807-27.

6. Scott LD, Rogers AE, Hwang WT, Zhang Y. Effects of critical care nurses' work hours on vigilance and patients' safety. Am J Crit Care. 2006;15(1):30-7.

7. Rogers AE, Hwang WT, Scott LD, Aiken LH, Dinges DF. The working hours of hospital staff nurses and patient safety. Health Aff (Millwood). 2004;23(4):202-12.

8. Durmer JS, Dinges DF. Neurocognitive consequences of sleep deprivation. Semin Neurol. 2005;25(1):117-29.

9. Boivin DB, Boudreau P. Impacts of shift work on sleep and circadian rhythms. Pathol Biol (Paris). 2014;62(5):292-301.

10. Palhares VC, Corrente JE, Matsubara BB. Association between sleep quality and quality of life in nursing professionals working rotating shifts. Rev Saúde Pública. 2014;48(4):594-601.

11. Geiger-Brown J, Rogers VE, Trinkoff AM, Kane RL, Bausell RB, Scharf SM. Sleep, sleepiness, fatigue, and performance of 12-hour-shift nurses. Chronobiol Int. 2012;29(2):211-9.

12. Muecke S. Effects of rotating night shifts: literature review. J Adv Nurs. 2005;50(4):433-9.

13. Myhren H, Ekeberg O, Stokland O. Job satisfaction and Burnout among Intensive Care Unit nurses and physicians. Crit Care Res Pract. $2013 ; 2013: 786176$.

14. Zhang XC, Huang DS, Guan P. Job burnout among critical care nurses from 14 adult intensive care units in northeastern China: a crosssectional survey. BMJ Open. 2014;4:e004813.

15. Rohlfs ICPM. Validação do teste de Brums para avaliação de humor em atletas e não atletas brasileiros [dissertação]. Florianópolis: Universidade do Estado de Santa Catarina, Centro de Educação Física, Fisioterapia e Desportos; 2006.

16. Akerstedt T, Gillberg M. Subjective and objective sleepiness in the active individual. Int J Neurosci. 1990;52(1-2):29-37.

17. Kaida K, Takahashi M, Akerstedt T, Nakata A, Otsuka Y, Haratani T, et al. Validation of the Karolinska sleepiness scale against performance and EEG variables. Clin Neurophysiol. 2006;117(7):1574-81.

18. Guerra PC, Oliveira NF, Terreri MTRA, Len CA. Sleep, quality of life and mood of nursing professionals of pediatric intensive care units. Rev Esc Enferm USP. 2016;50(2):277-83. DOI: http://dx.doi.org/10.1590/S0080-623420160000200014

19. Lombardi DA, Folkard S, Willetts JL, Smith GS. Daily sleep, weekly working hours, and risk of work-related injury: US National Health Interview Survey (2004-2008). Chronobiol Int. 2010;27(5):1013-30.

20. Clissold G, Smith P, Accutt B, Di Milia L. A study of female nurses combining partner and parent roles with working a continuous threeshift roster: the impact on sleep, fatigue and stress. Contemp Nurse. 2002;12(3):294-302.

21. Hughes RG, Rogers AE. Are you tired? Am J Nurs. 2004;104(3):36-8.

22. Portela LF, Rotenberg L, Waissmann W. Self-reported health and sleep complaints among nursing personnel working under $12 \mathrm{~h}$ night and day shifts. Chronobiol Int. 2004;21(6):859-70.

23. Shao MF, Chou YC, Yeh MY, Tzeng WC. Sleep quality and quality of life in female shift-working nurses. J Adv Nurs. 2010;66(7):1565-72.

24. Müller MR, Guimarães SS. Impacto dos transtornos do sono sobre o funcionamento diário e a qualidade de vida. Estudos Psicol (Campinas). 2007;24(4):519-28. 
25. Szentkiralyi A, Madarasz CZ, Novak M. Sleep disorders: impact on daytime functioning and quality of life. Expert Rev Pharmacoecon Outcomes Res. 2009;9(1):49-64.

26. Masento NA, Golightly M, Field DT, Butler LT, van Reekum CM. Effects of hydration status on cognitive performance and mood. Br J Nutr. 2014;111(10):1841-52.

27. Bloodworth C, Lea A, Lane S, Ginn R. Challenging the myth of the 12-hour shift: a pilot evaluation. Nurs Stand. 2001;15(29):33-6.

28. Richardson A, Dabner N, Curtis S. Twelve-hour shift on ITU: a nursing evaluation. Nurs Crit Care. 2003;8(3):103-8.

29. Lorenz SG. 12-hour shifts: an ethical dilemma for the nurse executive. J Nurs Adm. 2008;38(6):297-301.

\begin{tabular}{|l|l|l}
\hline (cc) BY & BY \\
\hline
\end{tabular} 